\title{
Laminated Wood Composite Design with Improved Acoustic Properties
}

\author{
Hamit Özyurt,* and Ferhat Özdemir
}

\begin{abstract}
Next-generation laminated wood composites were produced using waste poplar (Populus deltoides) veneer and polyvinyl acetate adhesive. Four experimental groups and one control group were created. Ten-layer laminated wood veneer samples were reinforced with natural rubber (Group A), linoleum (Group B), felt (Group C), and elastomeric sponge (Group D); these materials were used in the fifth adhesive layer (middle layer). The sound absorption coefficients of the control and experimental groups were tested via the impedance tube method, according to ASTM standard E1050 (2006). Attention was paid to the acoustic behavior at low frequencies $(63 \mathrm{~Hz}$ to $250 \mathrm{~Hz})$, mid frequencies $(250 \mathrm{~Hz}$ to $2000 \mathrm{~Hz})$, and high frequencies $(2000 \mathrm{~Hz}$ to $6300 \mathrm{~Hz})$. It was determined that the sound absorption coefficient of the experimental groups considerably increased. It can be suggested that the experimental groups be used as sound absorbing acoustic panels and the control group as sound reflective acoustic panels.
\end{abstract}

Keywords: Acoustic material design; Laminated wood composite; Natural rubber; Linoleum; Felt; Elastomeric sponge; Sound absorption coefficient

Contact information: Department of Forest Industry Engineering, Faculty of Forestry, Kahramanmaraş Sütçü İmam University, Kahramanmaraş 46100 Turkey; *Corresponding author: hcanozyurt@ gmail.com

\section{INTRODUCTION}

The need for wood and wood-based materials increases with the passage of time. Developing technology and an increase in the industrialization rate contribute to the variety of uses of wood-based materials. Laminated wood composites (LWC) are a type of structural composite timber. The history of veneers, which are the basis of wood-based building materials, go back to the period of the Pharaohs. The technique of obtaining a peeling veneer from logs was discovered in 1890 and started to be produced in wide boards. Laminated wood composite was first used in the production of propellers for fighter planes in the Second World War, and from the mid-1970s to the present it has been an important wood-based composite material (Dall1 2005).

Laminated wood composite is preferred as a building material in different areas of the construction industry. Building materials must have high physical properties. Laminated wood composite is generally produced from low density and low economic value tree species. As such, their physical properties are not at the desired level. The use of high density and economic value tree species increases the cost and is not preferred, since it decreases forest resources. For this reason, wood-based materials need to have a reinforced design.

The most important acoustic property of wood and wood-based materials is that although it is lightweight, the sound propagation speed is quite high. Due to its wooden material structure, it can both absorb and spread the sound. For this reason, wood material 
shows superior properties when compared with other acoustic materials. Thus, it is used both in the production of musical instruments and widely used as a wall covering in order to provide acoustic comfort in theatre, concert, cinema, and conference halls. The effect of wood-based materials used in interior construction is very important in absorbing sound, regulating sound waves, and preventing unwanted sound echoes caused by the reflection of sound on the walls (Berkel 1970).

Today, the production of wood-based products with different designs has increased and constitutes an important research area (Cowan 1991). Recently, when the authors looked at the studies about wood-based materials, it was seen that some materials, except for wood, are added to laminates using suitable adhesive, which yielded impressive results in terms of reinforcement the laminate (Rowlands et al. 1986; Pidaparti and Johnson 1996; Hallstrom and Grenestedt 1997; Fiorelli and Dias 2006; Güler and Subaş1 2012; Basterra et al. 2012; Bal and Özyurt 2015; Ghofrani et al. 2016; Özyurt 2020). In the last 20 years, using fiber-reinforced polymers to strengthen structural elements has been effective both economically and in terms of its structural performance (Taheri et al. 2009). In the literature, there was not sufficient research on the design and production of laminated wood composites as acoustic panels. The aim of this study was to produce laminated wood composites with improved acoustic properties.

\section{EXPERIMENTAL}

\section{Materials}

In this study, waste poplar (Populus deltoides) peeling veneer (with a thickness of $2.1 \mathrm{~mm}$ ) and polyvinyl acetate (PVAc) adhesive were used. The veneers were dried until the moisture content was 7\%. Knotted and cracked veneers were not used. Natural rubber, linoleum, felt, and elastomeric sponge (Fig. 1) were used in the reinforcement design of the laminated wood composite. The densities of the natural rubber, linoleum, felt, and elastomeric sponge were $750,800,57$, and $60 \mathrm{~kg} / \mathrm{m}^{3}$, respectively. The thickness of the materials was $5 \mathrm{~mm}$. The materials used in the research were supplied from a domestic manufacturer. 


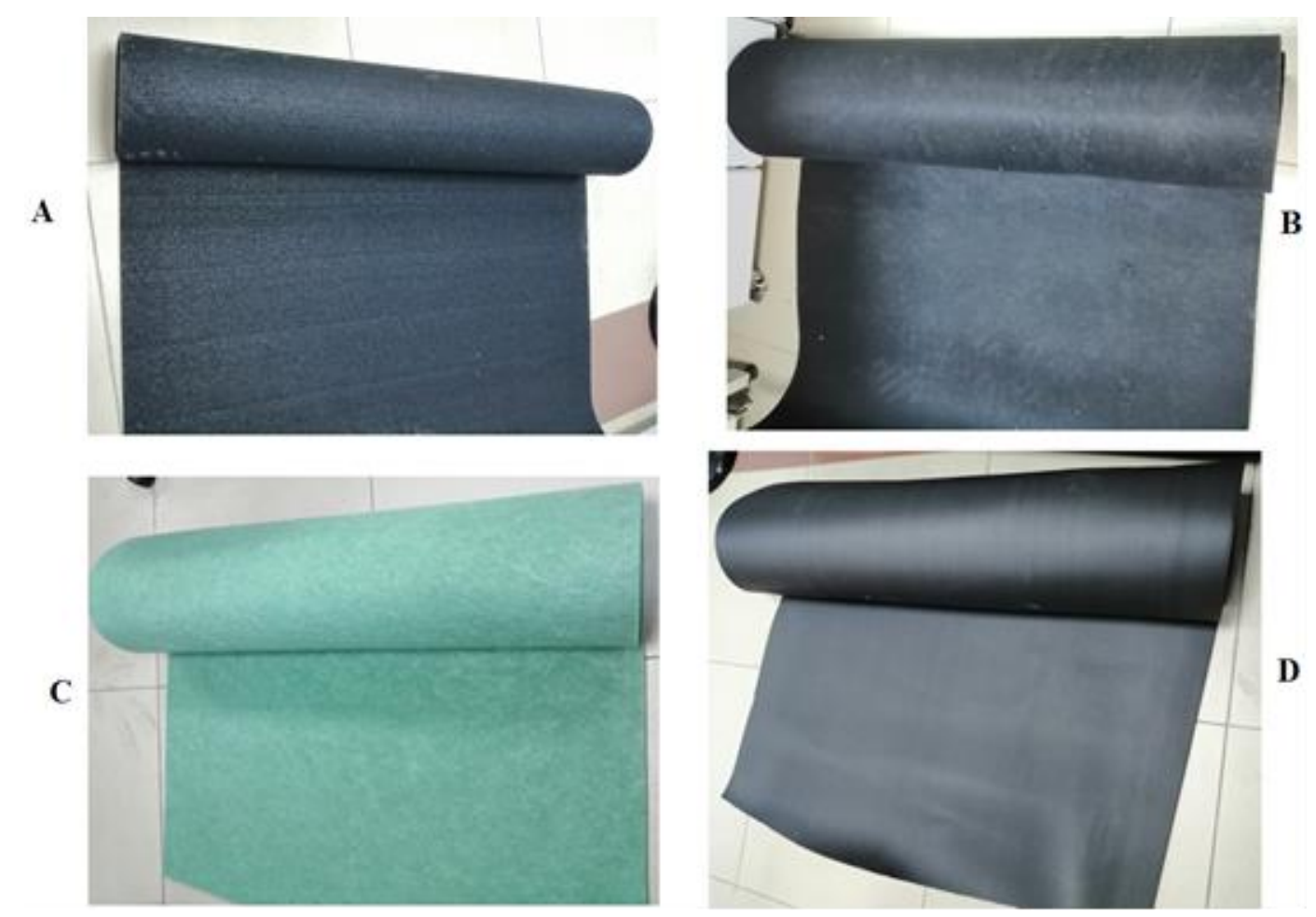

Fig. 1. Reinforcement materials: A) Rubber; B) Linoleum; C) Felt; and D) Elastomeric sponge

\section{Methods}

Approximately $250 \mathrm{~g} / \mathrm{m}^{2}$ of polyvinyl acetate (PVAc) adhesive was effused on the veneers, and then ten veneer sheets (fiber directions perpendicular to each other) were pressed in a hot press at a temperature of $50{ }^{\circ} \mathrm{C}$ and a pressure of $7 \mathrm{~kg} / \mathrm{cm}^{2}$. The laminated wood composite boards were produced as ten layers. One control group and four experimental groups (Fig. 2) were created. During the production of the experimental groups, four different materials were used as the middle layer, i.e., the fifth adhesive layer. These materials were as follows: natural rubber (Group A), linoleum (Group B), felt (Group C), and elastomeric sponge (Group D). Reinforcement materials were not used in the control group. Sixteen boards were produced for each group (laminated wood composite boards with a $100 \mathrm{~cm}$ width, $100 \mathrm{~cm}$ length, and $26 \mathrm{~mm} \pm 1 \mathrm{~mm}$ thickness), totaling 80 laminated wood composite boards. The test samples (Control, A, B, C and D groups) were conditioned at a temperature of $20{ }^{\circ} \mathrm{C} \pm 3{ }^{\circ} \mathrm{C}$ and a relative humidity of $65 \%$ $\pm 5 \%$ until a stable weight was reached (approximately $25 \mathrm{~d}$ ). The sound absorption coefficient (SAC) of the control and experimental groups was tested via the impedance tube method according to ASTM standard E1050 (2006). This impedance tube (Fig. 3) can measure low frequencies (63 to $1600 \mathrm{~Hz}$ ) with a large diameter tube $(99.8 \mathrm{~mm})$ and high frequencies with a small diameter tube $(29.95 \mathrm{~mm})$. The test samples (Fig. 4) used in the acoustic tests were obtained via precision cutting. The SAC results were analyzed via ANOVA (variance analysis) using the SPSS statistical software program. 


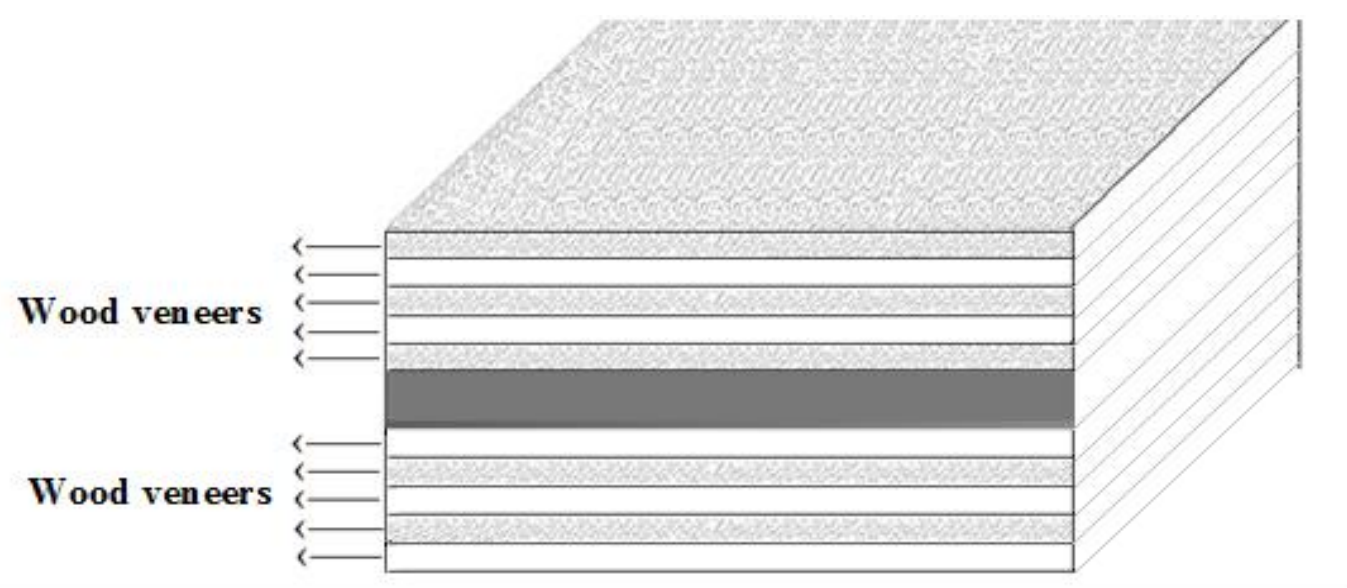

Fig. 2. Schematic image of the experimental groups

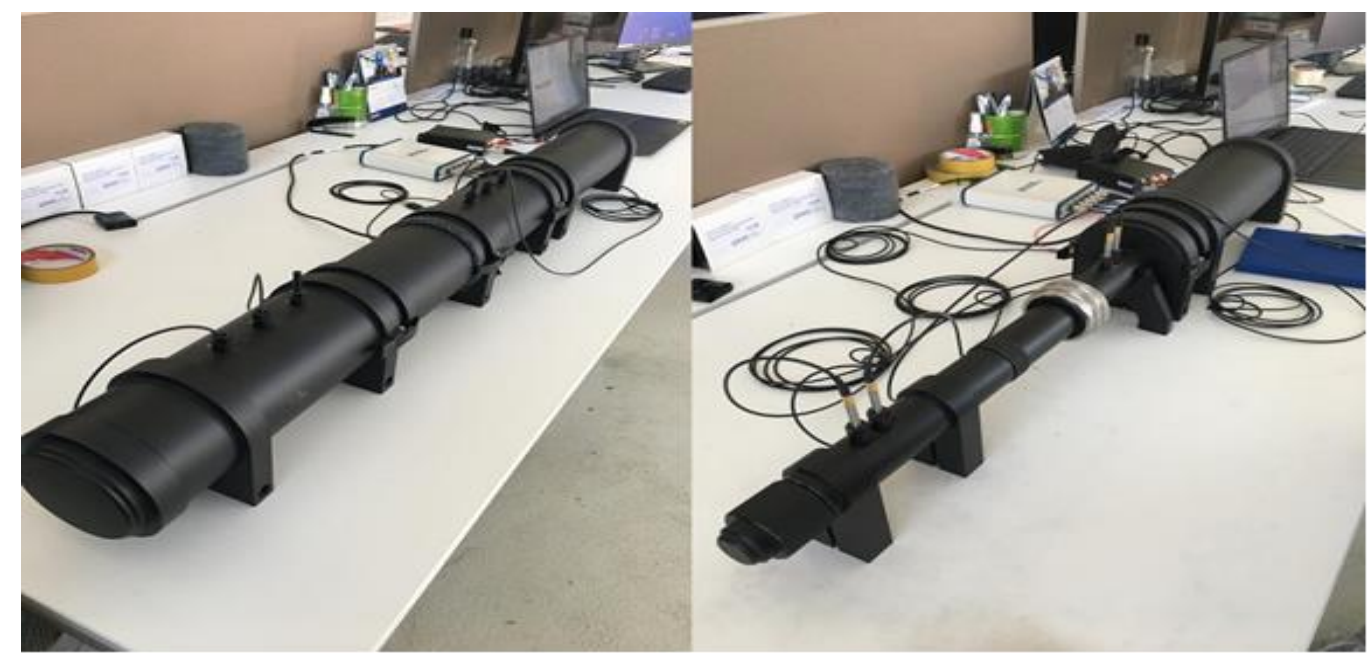

Fig. 3. Impedance tube measuring system (large diameter tube and small diameter tube)

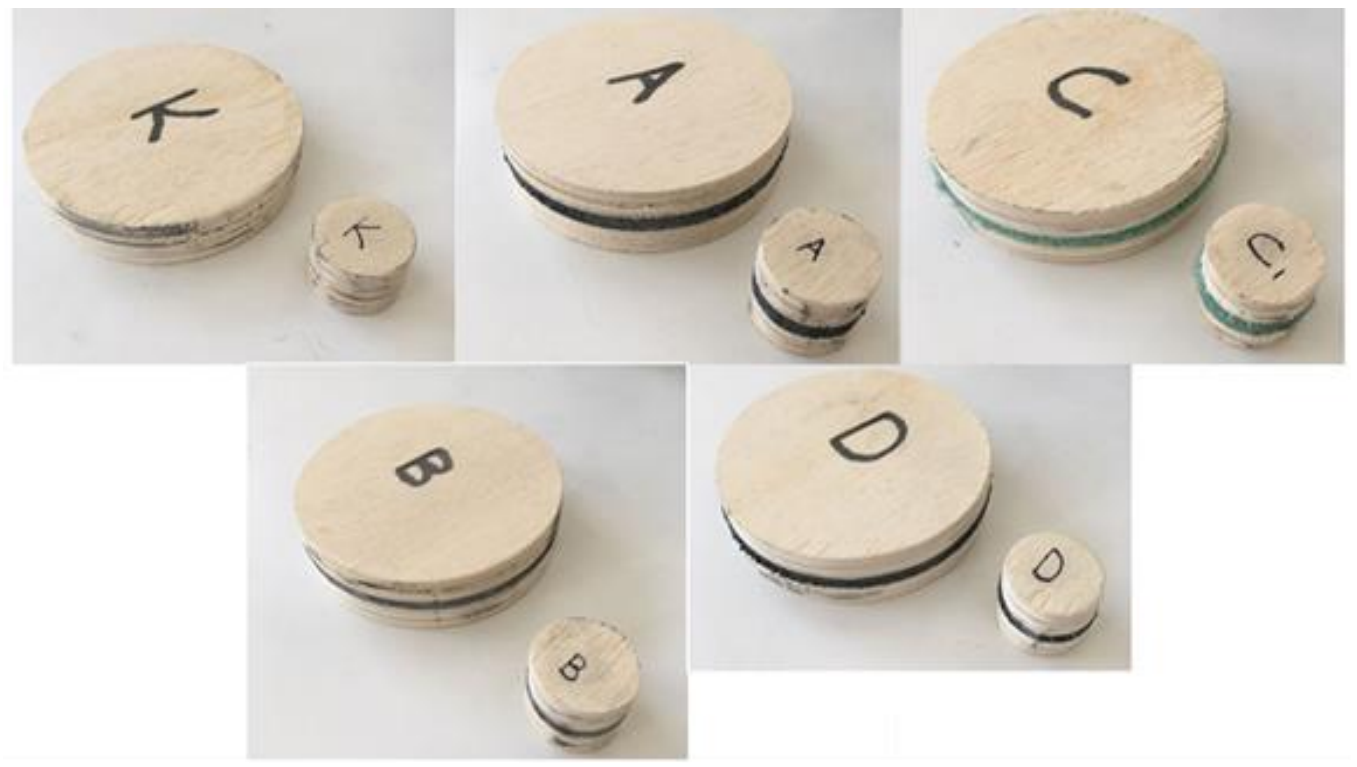

Fig. 4. Sound absorption coefficient test samples 


\section{RESULTS AND DISCUSSION}

When Tables 1 through 3 were examined in detail, the results of the ANOVA in the tables showed that the differences reinforcement designs had significant (a $p$-value less than 0.001) effects on the sound absorption coefficient values. The sound absorption coefficient (SAC) values of the experimental groups were higher than the SAC values of the control group. It was determined that the acoustic performances of the reinforced laminated wood composites had improved. In general, it was determined that the sound absorption coefficient values of the composite materials increased as the frequency increased. While the highest sound absorption performance was measured in the D group, the lowest sound absorption performance was measured in the control group.

Table 1. Sound Absorption Coefficient (SAC) Values $(63 \mathrm{~Hz}$ to $250 \mathrm{~Hz})$ and ANOVA Results ( $p$-value equals 0.05 )

\begin{tabular}{|c|c|c|c|c|c|c|c|}
\hline \multirow{2}{*}{ Group } & \multicolumn{7}{|c|}{ Frequency $(\mathrm{Hz})$} \\
\hline & $63 \mathrm{~Hz}$ & $80 \mathrm{~Hz}$ & $100 \mathrm{~Hz}$ & $125 \mathrm{~Hz}$ & $160 \mathrm{~Hz}$ & $200 \mathrm{~Hz}$ & $250 \mathrm{~Hz}$ \\
\hline Control & 0.01 & 0.02 & 0.03 & 0.05 & 0.06 & 0.05 & 0.05 \\
\hline$A$ & 0.05 & 0.07 & 0.08 & 0.11 & 0.12 & 0.15 & 0.17 \\
\hline$B$ & 0.04 & 0.06 & 0.08 & 0.10 & 0.22 & 0.30 & 0.40 \\
\hline C & 0.03 & 0.04 & 0.05 & 0.08 & 0.10 & 0.14 & 0.16 \\
\hline $\mathrm{D}$ & 0.08 & 0.08 & 0.10 & 0.13 & 0.15 & 0.16 & 0.18 \\
\hline$x$ & 0.042 & 0.054 & 0.068 & 0094 & 013 & 016 & 0.192 \\
\hline $\mathrm{S}$ & 0.02 & 0.02 & 0.02 & 0.03 & 0.06 & 0.08 & 0.12 \\
\hline $\mathrm{X} \min$ & 0.01 & 0.02 & 0.03 & 0.05 & 0.06 & 0.05 & 0.05 \\
\hline $\mathrm{X} \max$ & 0.08 & 0.08 & 0.10 & 0.13 & 0.22 & 0.30 & 0.40 \\
\hline$(P \leq 0.05)$ & $0.0000^{*}$ & $0.0000^{*}$ & $0.0000^{*}$ & $0.0000^{*}$ & $0.0000^{*}$ & $0.0000^{*}$ & $0.0000^{\star}$ \\
\hline
\end{tabular}

Table 2. Sound Absorption Coefficient (SAC) Values $(315 \mathrm{~Hz}$ to $1250 \mathrm{~Hz})$ and ANOVA Results ( $p$-value equals 0.05 )

\begin{tabular}{|c|c|c|c|c|c|c|c|}
\hline \multirow{2}{*}{ Group } & \multicolumn{7}{|c|}{ Frequency $(\mathrm{Hz})$} \\
\cline { 2 - 8 } & $315 \mathrm{~Hz}$ & $400 \mathrm{~Hz}$ & $500 \mathrm{~Hz}$ & $630 \mathrm{~Hz}$ & $800 \mathrm{~Hz}$ & $1000 \mathrm{~Hz}$ & $1250 \mathrm{~Hz}$ \\
\hline Control & 0.05 & 0.06 & 0.08 & 0.10 & 0.11 & 0.12 & 0.14 \\
\hline A & 0.21 & 0.23 & 0.30 & 0.37 & 0.44 & 0.46 & 0.38 \\
\hline B & 0.35 & 0.39 & 0.42 & 0.40 & 0.40 & 0.40 & 0.42 \\
\hline C & 0.19 & 0.22 & 0.25 & 0.27 & 0.34 & 0.30 & 0.31 \\
\hline D & 0.20 & 0.25 & 0.33 & 0.35 & 0.36 & 0.38 & 0.40 \\
\hline \multicolumn{7}{|l|}{} \\
\hline X & 0.20 & 0.23 & 0.276 & 0.298 & 0.33 & 0.332 & 0.33 \\
\hline S & 0.1 & 0.1 & 0.12 & 0.12 & 0.12 & 0.13 & 0.11 \\
\hline X min & 0.05 & 0.06 & 0.08 & 0.10 & 0.11 & 0.12 & 0.14 \\
\hline X max & 0.35 & 0.39 & 0.42 & 0.40 & 0.44 & 0.46 & 0.42 \\
\hline (P $\leq 0.05)$ & $0.0000^{*}$ & $0.0000^{*}$ & $0.0000^{*}$ & $0.0000^{*}$ & $0.0000^{*}$ & $0.0000^{*}$ & $0.0000^{*}$ \\
\hline $\begin{array}{l}\text { Note: X: average value; S: the standard deviation; X min: minimum value; and X max: } \\
\text { maximum value }\end{array}$ \\
\hline
\end{tabular}


Table 3. Sound Absorption Coefficient (SAC) Values $(1600 \mathrm{~Hz}$ to $6300 \mathrm{~Hz})$ and ANOVA Results ( $p$-value equals 0.05 )

\begin{tabular}{|c|c|c|c|c|c|c|c|}
\hline \multirow{2}{*}{ Group } & \multicolumn{7}{|c|}{ Frequency $(\mathrm{Hz})$} \\
\hline & $1600 \mathrm{~Hz}$ & $2000 \mathrm{~Hz}$ & $2500 \mathrm{~Hz}$ & $3150 \mathrm{~Hz}$ & $4000 \mathrm{~Hz}$ & $5000 \mathrm{~Hz}$ & $6300 \mathrm{~Hz}$ \\
\hline Control & 0.15 & 0.17 & 0.16 & 0.16 & 0.19 & 0.20 & 0.28 \\
\hline$A$ & 0.50 & 0.55 & 0.51 & 0.59 & 0.65 & 0.70 & 0.84 \\
\hline$B$ & 0.44 & 0.45 & 0.47 & 0.49 & 0.51 & 0.55 & 0.70 \\
\hline C & 0.30 & 0.35 & 0.40 & 0.50 & 0.55 & 0.58 & 0.76 \\
\hline $\mathrm{D}$ & 0.55 & 0.60 & 0.57 & 0.66 & 0.74 & 0.79 & 0.92 \\
\hline & & & & & & & \\
\hline $\mathrm{X}$ & 0.388 & 0.424 & 0.422 & 0.48 & 0.528 & 0.564 & 0.70 \\
\hline $\mathrm{S}$ & 0.16 & 0.17 & 0.15 & 0.19 & 0.2 & 0.22 & 0.24 \\
\hline$X \min$ & 0.15 & 0.17 & 0.16 & 0.16 & 0.19 & 0.20 & 0.28 \\
\hline $\mathrm{X} \max$ & 0.55 & 0.60 & 0.57 & 0.66 & 0.74 & 0.79 & 0.92 \\
\hline$(P \leq 0.05)$ & $0.0000^{*}$ & $0.0000^{*}$ & $0.0000^{*}$ & $0.0000^{*}$ & $0.0000^{*}$ & $0.0000^{*}$ & $0.0000^{*}$ \\
\hline
\end{tabular}

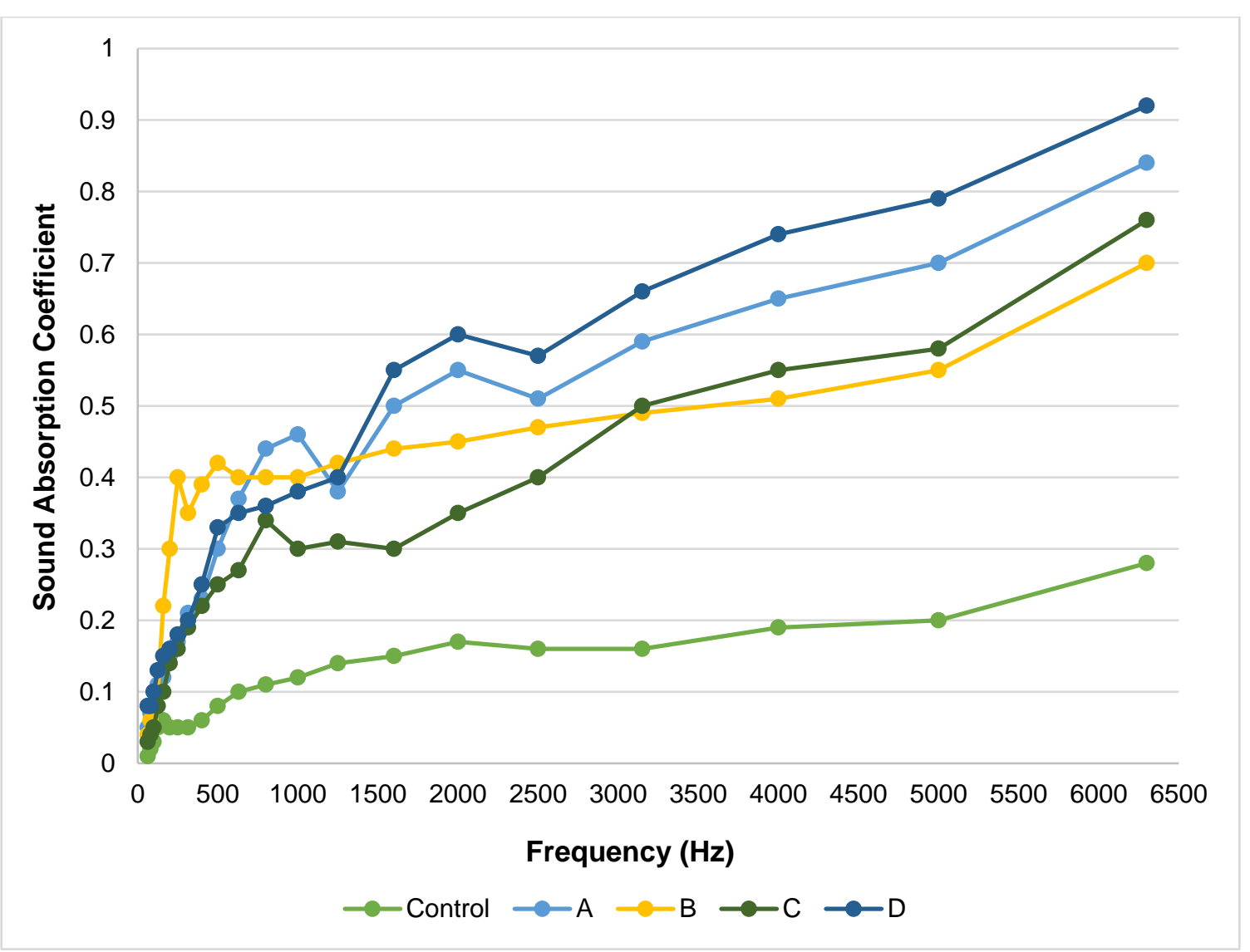

Fig. 5. Low, mid, and high frequency sound absorption coefficient values of the control A, B, C and D groups

Figure 5 shows that the natural rubber, linoleum, felt, and elastomeric sponge all improved the acoustic properties of the composite materials belonging to the experimental groups. The low frequency $(63 \mathrm{~Hz}$ to $250 \mathrm{~Hz}$ ) sound absorption coefficient values (the highest) of the control A, B, C, and D groups were determined to be $0.06,0.17,0.40,0.16$, 
and 0.18 , respectively. The mid-frequency $(250$ to $2000 \mathrm{~Hz}$ ) sound absorption coefficient values (maximum) of the control A, B, C, and D groups were determined to be $0.17,0.55$, $0.45,0.35$, and 0.60 , respectively. The high frequency ( 2000 to $6300 \mathrm{~Hz}$ ) sound absorption coefficient values (the best) of the control A, B, C, and D groups were determined to be $0.28,0.84,0.70,0.76$, and 0.92 , respectively. There was a positive relationship between the sound absorption coefficient (SAC) value and frequency $(\mathrm{Hz})$. It was determined that there was a sudden increase in the sound absorption coefficient values of the composite materials within the frequency range of 5000 to $6300 \mathrm{~Hz}$. While the highest sound absorption performance at a low frequency was measured in group B (produced using linoleum), the highest sound absorption performance at a medium and high frequency was measured in group D (produced using elastomeric sponge). However, the best sound absorption results at $800 \mathrm{~Hz}$ and $1000 \mathrm{~Hz}$ frequencies were found in group A (produced using natural rubber). When the results were examined in detail, compared to the control group, the percentage increase of the SAC of the A, B, C, and D groups, with respect to the low frequency, mid frequency, and high frequency, were $183 \%-223 \%-200 \%, 566 \%$ $-164 \%-150 \%, 166 \%-105 \%-171 \%$, and $200 \%-252 \%-228 \%$, respectively. The sound absorption coefficient (SAC) had a value between (0) and (1). As the SAC value gets closer to 0 , it is defined as a sound reflecting material; as it gets closer to 1 , it is defined as a sound absorbing material. While the control, A, C, and D groups were sound reflectors at a low frequency $(\mathrm{Hz})$, the B group was a sound absorber. The A, B, C, and D groups were sound absorbers at a mid and high frequency $(\mathrm{Hz})$. While the control group was a sound reflector at a mid frequency $(\mathrm{Hz})$, it was a sound absorber at a high frequency $(5000$ and $6300 \mathrm{~Hz})$.

Wood-based materials with a high density have a higher sound absorption performance compared to wood materials with a low density. However, the use of highdensity wood materials is not preferred due to its contribution to decreasing forest resources. It is understood that the elastomeric sponge, which is one of the lowest density materials among the reinforcement materials used in this research, had the highest sound absorption performance (group D). In this research, it was emphasized that acoustic materials can be produced from waste wood veneers with low density. In addition, this study showed that high acoustic performance can be obtained from laminated wood composites. In addition to all these, waste poplar veneer, natural rubber, linoleum, felt, and elastomeric sponge are recyclable materials, so the produced composite materials have a low carbon footprint.

In a previous study, plywood was produced using wood veneer, methylene diphenyl diisocyanate (MDI), and waste rubber. The acoustic properties of the produced composite materials were investigated. According to the results obtained, it was determined that the composite material produced using waste rubber had a higher sound absorption performance than the commercial plywood reported in the literature. In addition, they reported that the acoustic performance of the material improved as the use of beech veneers in the lamination application increased (Ghofrani et al. 2016).

\section{CONCLUSIONS}

1. The acoustic properties of the composite materials belonging to the experimental groups improved considerably. It has been found that natural rubber, linoleum, felt, and elastomeric sponge are effective in the production of acoustic materials. 
2. Among the reinforcement materials, the highest acoustic performance was determined in elastomeric sponge.

3. The results suggest that the composite materials belonging to the experimental groups (A, B, C, and D) be used as sound absorbing acoustic panels and the composite materials belonging to the control group can be used as sound reflective acoustic panels.

4. High-tech materials can be produced with the lamination technique when applied to waste wood veneers.

\section{ACKNOWLEDGMENTS}

The authors thank the Research Fund (BAP) of the Kahramanmaras Sutçu Imam University for financial support of this study (Project No: 2020/1-15 D). The authors also thank the Higher Education Council of Turkey (YOK) for the financial support of this study (YOK 100/2000 Ph.D. Project Scholarship Program, Research area: Industrial Products Design).

\section{REFERENCES CITED}

ASTM E1050 - 98 (2006). "Standard test method for impedance and absorption of acoustical materials using a tube, two microphones and a digital frequency analysis system," ASTM International, West Conshohocken, PA.

Bal, B. C., and Özyurt, H. (2015). "Some technological properties of laminated veneer lumber reinforced with woven glass fiber," Kahramanmaraş Sütçü Imam University Journal of Engineering Sciences 18(1), 9-16.

Basterra, L. A., Acuña, L., Casado, M., López, G., and Bueno, A. (2012). "Strength testing of poplar duo beams, Populus x euramericana (Dode) Guinier cv. I-214, with fibre reinforcement," Construction and Building Materials 36, 90-96.

Berkel, A. (1970). Wood Material Technology, Faculty of Forestry Publications. Publication No. 147. Istanbul University, Istanbul.

Cowan, H. J. (1991). Handbook of Architectural Technology, Van Nostrand Reinhold, New York, NY.

Dall, G. (2005). The Research of Laminated Veneer Lumber Manufacture Possibilities in Turkey and its Technological Properties, Master's Thesis, İstanbul University, İstanbul, Turkey.

Fiorelli, J., and Dias, A. A. (2006). "Fiberglass-reinforced glulam beams: Mechanical properties and theoretical model," Materials Research 9(3), 263-269. DOI: 10.1590/S1516-14392006000300004

Ghofrani, M., Ashori, A., Rezvani, M. H., and Ghamsari, F. A. (2016). "Acoustical properties of plywood/waste tire rubber composite panels," Measurement 94, 382387. DOI: 10.1016/j.measurement.2016.08.020

Güler, C., and Subaşı, S. (2012). "Carbon and glass fiber reinforced laminated scots pine (Pinus sylvestris L.)," Kahramanmaraş Sütçü Imam University Journal of Engineering Sciences SI, 78-82.

Hallström, S., and Grenestedt, J. L. (1997). "Failure analysis of laminated timber beams 
reinforced with glass fiber composites," Wood Science and Technology 31, 17-34. DOI: $10.1007 / \mathrm{BF} 00705697$

Özyurt, H. (2020). "Design and properties of composite sustainable building material by using waste HDPE," Mühendislik Bilimleri ve Tasarım Dergisi 8(3), 777-782. DOI: $10.21923 /$ jesd.741478

Pidaparti, R. M. V., and Johnson, K. (1996). “Composite lamination to wood,” Polymers and Polymer Composites 4(2), 125-128.

Rowlands, R. E., Deweghe, R. P. V., Laufenberg, T. L., and Krueger, G. P. (1986). "Fiber-reinforced wood composites," Wood and Fiber Science 18(1), 39-57.

Taheri, F., Nagaraj, M., and Khosravi, P. (2009). "Buckling response of glue-laminated columns reinforced with fiber-reinforced plastic sheets," Composite Structures 88(3), 481-490. DOI: 10.1016/j.compstruct.2008.05.013

Article submitted: September 7, 2021; Peer review completed: November 6, 2021;

Revised version received and accepted: November 19, 2021; Published: November 23, 2021.

DOI: $10.15376 /$ biores.17.1.460-468 